\title{
Descriptive epidemiology of intracranial hemorrhage patterns and the main complaints motivating brain computed tomography scans in Northern Portugal
}

\author{
Lino Mascarenhas* \\ Neurosurgery Service, Centro Hospitalar de Vila Nova de Gaia/Espinho (CHVNG/E). Vila Nova de Gaia, Portugal
}

\begin{abstract}
Background/Aims: This study aimed at documenting the patterns of intracranial hemorrhage encountered by means of brain computed tomography (CT) scan and characterizing the chief complaint that led to the diagnosis. Methods: All the brain CT scans performed in a hospital serving 334,081 inhabitants in a 1-year period were reviewed. Categories of clinical situations and imaging findings were correlated among themselves and with population data to obtain incidence rates. Results: $A$ total of 8516 patients (M/F ratio 0.83; mean age 63.31) underwent brain CT scans and hemorrhage was present in 448 (5.26\%). Head injury was the most frequent complaint motivating brain CT scan (30.11\%) and acute subdural hemorrhage the most frequent pattern encountered (37.05\%). An incidence rate of intracranial hemorrhage of 134.10 , a global incidence rate of head injury of 767.48, and an incidence rate of hemorrhage of 76.33/100,000/year in the context of trauma were found. Incidence rates of hemorrhagic patterns more likely to be associated with a spontaneous origin add up to 45.2/100,000/year. Conclusion: Traumatic patterns of hemorrhage are more frequent than those of spontaneous nature and head injury the most frequent indication for brain CT scan study. Although within the ranges reported in literature, incidence rates of hemorrhage in the studied population rank low for trauma and spontaneous subarachnoid and high for intracerebral. This indicator serves to characterize the health status of the community.
\end{abstract}

Key words: Incidence. Head injury. Intracerebral hemorrhage. Spontaneous subarachnoid hemorrhage. Portugal.

\section{Epidemiología descriptiva de los patrones de hemorragia intracraneal y de las quejas principales motivadoras de TAC cerebral en el Norte de Portugal}

\section{Resumen}

Antecedentes/Objetivos: Este estudio tuvo como objetivo documentar los patrones de hemorragia intracraneal encontrados mediante tomografía computarizada cerebral y caracterizar la queja principal que condujo al diagnóstico. Métodos: se revisaron todas las tomografías cerebrales realizadas en un hospital que atendía a 334,081 habitantes en un período de un año. Las categorías de situaciones clínicas y los hallazgos de imagen se correlacionaron entre sí y con los datos de población

\section{Correspondence:}

*Lino Mascarenhas

Neurocirugia, CHVNGE

Rua Conceição Fernandes, s/n

Date of reception: 13-06-2018

Date of acceptance: 23-11-2018

4434-502, Vila Nova de Gaia, Portugal

E-mail: linomasc@gmail.com license (http://creativecommons.org/licenses/by-nc-nd/4.0/). 
para obtener tasas de incidencia. Resultados: 8.516 pacientes (relación M/F 0.83; edad media 63.31) se sometieron a tomografías computarizadas cerebrales y existía hemorragia en 448 (5.26\%). Traumatismo craneal fue la queja más frecuente que motivó la TC cerebral (30.11\%) y la hemorragia subdural aguda el patrón más frecuente encontrado (37.05\%). Se encontró una tasa de incidencia de hemorragia intracraneal de 134.10, una tasa de incidencia global de traumatismo craneal de 767.48 y una tasa de incidencia de hemorragia de 76.33 por 100,000 por año en el contexto de trauma. Las tasas de incidencia de patrones hemorrágicos más propensos a asociarse con un origen espontáneo suman 45.2 por 100,000 por año. Conclusión: Los patrones traumáticos de hemorragia son más frecuentes que los de naturaleza espontánea, y el traumatismo craneal es la indicación más frecuente para el estudio de tomografía computarizada cerebral. Aunque dentro de los rangos reportados en la literatura, las tasas de incidencia de hemorragia en la población estudiada son bajas para traumatismo y subaracnoidea espontánea, y altas para intracerebral. Este indicador sirve para caracterizar el estado de salud de la comunidad.

Palabras clave: Incidencia. Traumatismo craneal. Hemorragia intracerebral. Hemorragia subaracnoidea espontánea. Portugal.

\section{Introduction}

It is of common medical knowledge that the incidence of intracranial hemorrhage of traumatic and spontaneous origins is dependent on multiple variables such as, and among others, access to medication and medical care, lifestyle, genetic predisposition, traffic hazards, work security conditions, and crime issues. Despite the difficulty in calculating the weight that each variable may have in the incidence of intracranial hemorrhage, this indicator can serve to characterize the health status of a community. Computed tomography (CT) scan is the most widely used method for diagnosing intracranial hemorrhage and its efficacy is well defined. At present, available software used for viewing and archiving medical imaging, as well as reports, allows for easy access to all the examinations performed in a certain period of time and to the diagnoses made. The aim of this study was to document the patterns of intracranial hemorrhage encountered by means of brain CT scan in a large urban community in Northern Portugal, and further characterize the chief complaint that led to the diagnosis, providing ciphers in the perspective of descriptive epidemiology that are not readily available. Monitoring the incidence of pathologies that can have devastating neurological outcomes such as head injury and hemorrhagic stroke is of uttermost relevance; if rates encountered compare unfavorably to those of others, study and adoption of efficacious measures aimed at the prevention of these disorders and events should lead to their decrease and to consequent improvements in the health status of the community.

\section{Methods}

The population studied had access to one public hospital with a neurological and neurosurgical unit that had recently started to cover emergency cases. On the one hand, this obviated the need to transfer patients from the hospital to referral institutions as well as direct referral to those institutions from the street. On the other hand, the catchment area was well defined since at that initial time, the hospital aimed only at its direct catchment area, and hospitals from the potential indirect catchment area continued to refer patients to previously established referral institutions. A population census had been performed in the year before the study period that provided an accurate figure of 334,081 inhabitants in the direct catchment area of the hospital (two municipalities) ${ }^{1}$. Private facilities available in the area did not, in general, assume surgical cases or complex inpatients, referring them to the public hospital. It was assumed that patients living in other locations that were diagnosed and treated in the hospital ("passers-by") would compensate for potential patients of the hospital's direct catchment area treated at outside institutions.

The software used for archiving and viewing of imaging was used to review all the brain CT scans performed in the hospital in a 1-year period (April 2012-March 2013 - Philips Brilliance CT 64 Channel device), along with the summarized clinical information that motivated the examination, the report performed as well as the age and gender of the patients. All the information was obtained from one computer program (Pacs Sectra). Categories used to classify the chief complaint provided by the referring physician were head injury, speech and cognition complaints, headaches, seizures, stupor, syncope, "follow-up," sensory complaints, motor complaints, post-operative, and "not provided." If an event of acute trauma was present, this was assumed as the chief complaint, unless it was subsequent to another event such as syncope. If more than one category was present, for example, speech 
and motor deficits, the category assumed was the one that the referring clinician mentioned first in the clinical information. Categories used to classify the patterns of intracranial hemorrhage reported by the radiologist were acute subdural and traumatic subarachnoid, epidural, spontaneous cerebral corticosubcortical, spontaneous basal ganglia, spontaneous cerebellar, parenchymal contusion, chronic subdural, ventricular, brainstem, and spontaneous subarachnoid. If more than one category was present, for example, basal ganglia and ventricular, the category assumed was the one that the radiologist described as predominant. If this could not be inferred from the report, the category assumed was the one mentioned first by the radiologist. A volumetric subclassification was not undertaken in this study, meaning that a hemorrhage classified as epidural could range from a minor film to massive. Overlap of categories is well acknowledged as a confounding factor, but these typifications had to be employed given the large size of the sample and the multitude of possible clinical situations and imaging findings. Sorting of data and calculations (including Chi-square analysis/Fisher's exact test with mid-P method/t-test/95\% confidence limits score of Wilson) were performed with widely available spreadsheet and statistical analysis software (Microsoft Excel and OpenEpi).

\section{Results}

A total of 8516 patients ( 3855 males, $M / F$ ratio 0.83 ; mean age in years 63.31; median 67.72; range 0.15102.30; standard deviation 20.24) underwent 10,884 brain CT scans, implying a global ratio of 1.28 CT scans per patient. This ratio of CT scans per patient deserved further analysis and was viewed in the context of repeat CT scans to follow hemorrhagic pathology previously encountered, as well as new clinical situations affecting the patients, either of the same, or from a different nature. The number of patients that underwent repeat CT scan was indeed 1379 (16.19\%), and they underwent 3733 CT scans, implying a corrected ratio of 2.70 per patient in these patients. Hemorrhage was present in the initial CT scan of 303 of the patients that underwent repeat scans (21.97\%). Thirty-two initially "unidentified" patients that possibly underwent repeat scans as identified patients could contribute to this figure as well. A uniform criterion to distinguish between repeat CT scans that represented follow-up of know situations versus those that represented concomitant or new clinical situations was not achieved, and
Table 1. Frequencies of chief complaints motivating brain CT scan

\begin{tabular}{|l|c|c|}
\hline Chief complaint & Patients (n) & Percentage/(*) \\
\hline Head injury & 2564 & $30.11(29.14-31.09)$ \\
\hline Cognition and speech & 1273 & $14.95(14.21-15.72)$ \\
\hline Headache & 1260 & $14.80(14.06-15.57)$ \\
\hline Sensory & 909 & $10.67(10.04-11.35)$ \\
\hline Motor & 729 & $8.56(7.98-9.17)$ \\
\hline Syncope & 472 & $5.54(5.07-6.04)$ \\
\hline Seizures & 369 & $4.33(3.92-4.78)$ \\
\hline Not provided & 296 & $3.48(3.10-3.88)$ \\
\hline Follow-up & 286 & $3.36(2.99-3.76)$ \\
\hline Stupor & 280 & $3.29(2.93-3.68)$ \\
\hline Post-operative & 78 & $0.92(0.73-1.14)$ \\
\hline Total & 8516 & 100.00 \\
\hline
\end{tabular}

**95\% Confidence limits score (Wilson). CT: Computed tomography

these subsequent CT scans were excluded from the remaining analysis. It is acknowledged that this may underestimate certain ciphers. The frequency of chief complaints that motivated the first CT scan performed by the patients in the study period is displayed in table 1. Hemorrhage was present in $448(5.26 \%)$ of these initial CT scans. The frequency of hemorrhage per chief indication is detailed in table 2, and Chi-square analysis with $p<0.05$ supported relevant differences in the proportions found; the frequency of patterns encountered is summarized in table 3 . Incidence rates of the diverse situations are shown in table 4. Incidence rates were calculated using as numerator the registered occurrences of clinical situations/imaging findings obtained from the analysis of the CT scans in the 1-year period multiplied by 100,000 and as denominator the 334,081 inhabitants of the direct catchment area of the hospital. Certain age and gender variations according to clinical context and type of hemorrhage are reported in table 5.

\section{Discussion}

The methodology employed in the present study for obtaining the cases of intracranial hemorrhage by means of CT scan review allowed for a comprehensive analysis of the phenomenon, in both the traumatic and spontaneous forms. With the exception of the early 
Table 2. Frequency of hemorrhage by chief complaint

\begin{tabular}{|l|c|c|c|}
\hline Chief complaint & Patients without hemorrhage (n) & Patients with hemorrhage (n) & Percentage hemorrhage by complaint/**) \\
\hline Head injury & 2365 & 199 & $7.76(6.78-8.86)$ \\
\hline $\begin{array}{l}\text { Cognition and } \\
\text { speech }\end{array}$ & 1237 & 36 & $2.83(2.05-3.89)$ \\
\hline Headache & 1236 & 24 & $1.90(1.28-2.81)$ \\
\hline Sensory & 899 & 10 & $1.10(0.59-2.01)$ \\
\hline Motor & 695 & 34 & $4.66(3.35-6.44)$ \\
\hline Syncope & 461 & 11 & $2.33(1.30-4.12)$ \\
\hline Seizures & 360 & 9 & $2.44(1.28-4.57)$ \\
\hline Not provided & 284 & 12 & $4.05(2.33-6.95)$ \\
\hline Follow-up & 239 & 47 & $16.43(12.59-21.17)$ \\
\hline Stupor & 249 & 31 & $11.07(7.91-15.29)$ \\
\hline Post-operative & 43 & 35 & $44.87(34.33-55.89)$ \\
\hline
\end{tabular}

**95\% Confidence limits score (Wilson)

Table 3. Predominant type of hemorrhage encountered in brain CT scan

\begin{tabular}{|l|c|c|}
\hline Type of hemorrhage & Patients $(\mathbf{n})$ & Percentage/(*) \\
\hline Acute subdural & 166 & $37.05(32.71-41.62)$ \\
\hline Cerebellar & 10 & $2.23(1.21-4.05)$ \\
\hline Contusion & 72 & $16.07(12.96-19.76)$ \\
\hline Corticosubcortical & 58 & $12.95(10.15-16.37)$ \\
\hline Chronic subdural & 30 & $6.70(4.73-9.39)$ \\
\hline Epidural & 17 & $3.79(2.38-5.99)$ \\
\hline Basal ganglia & 61 & $13.62(10.75-17.1)$ \\
\hline Spontaneous & 18 & $4.02(2.55-6.26)$ \\
\hline subarachnoid & 4 & $0.89(0.34-2.27)$ \\
\hline Brainstem & 12 & $2.68(1.53-4.62)$ \\
\hline Ventricular & 448 & 100.00 \\
\hline Total & & \\
\hline
\end{tabular}

**95\% Confidence limits score (Wilson)

infancy period in which transfontanelar ultrasonography is many times employed, current practice indicates CT scan as the appropriate examination for diagnosis and follow-up. This approach obviated certain selection bias such as department origin, surgical intervention, or etiologic (either traumatic or spontaneous cases). Studies employing a selection of cases using codes from the International Classification of Diseases (ICD) or Diagnosis Related Groups (DRGs) may tend to analyze only patients that were categorized as inpatients, i.e. remaining more than $24 \mathrm{~h}$ in the hospital. They may not be able to measure the phenomenon of patients that suffer minor head injury and have indeed suffered head injury, but do not have lesions in the $\mathrm{CT}$, and are, therefore, discharged from the emergency room. These patients are users of the health system and resources but may not be accounted for in the head injury statistics. In this study, this can be easily found by looking up head injury indication for CT scan and no intracranial hemorrhage in CT scan result. Another potential pitfall of studies using ICD or DRG codes might have to do with transferred patients. A patient admitted for surveillance in a local hospital who later deteriorates and undergoes surgery in a referral institution, and even later gets transferred again to the local institution, might be counted 3 times for epidemiological purposes with the coding methodology.

In the general characterization of the sociological scenario of the population in study, it would be worth mentioning: relatively easy and affordable access to medical care, as well as antihypertensive, antidyslipidemic, and anticoagulant medication; promotion of physical activity 


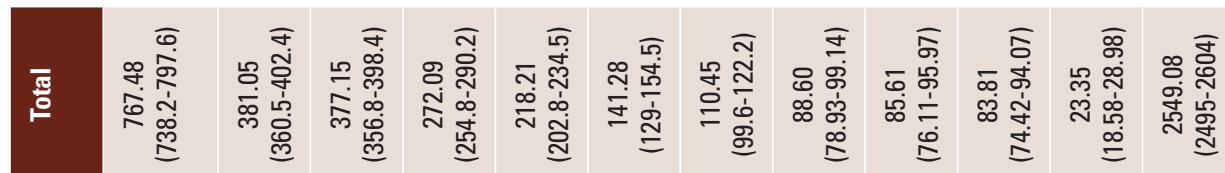

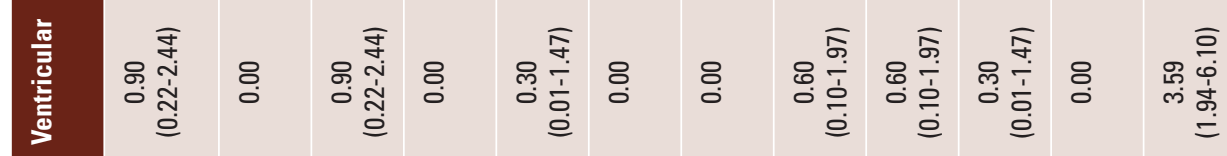

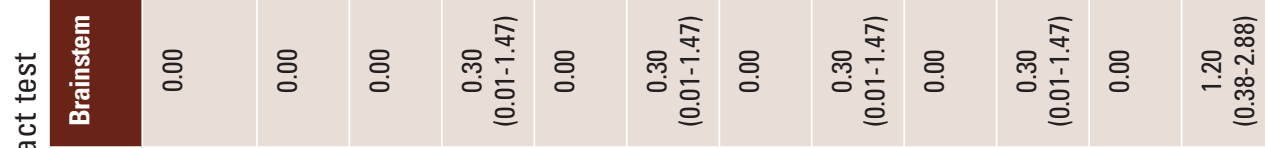

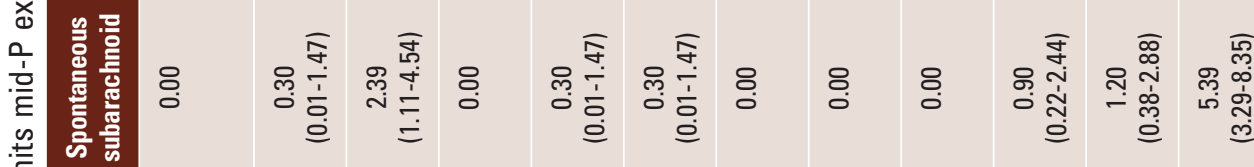

高

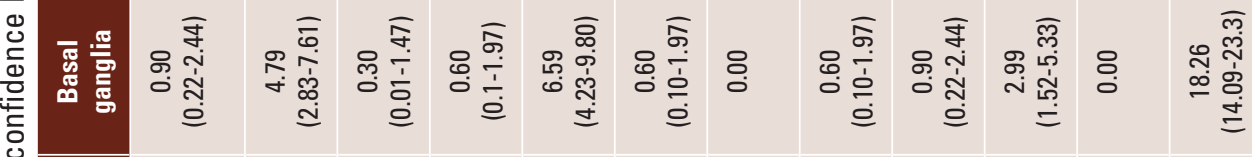

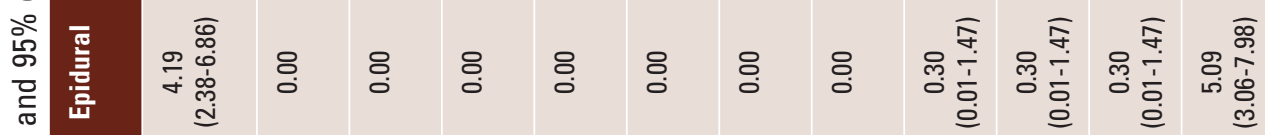
$\stackrel{\bar{\varpi}}{\stackrel{\bar{d}}{7}}$

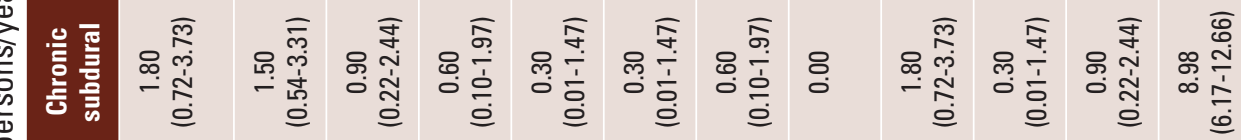

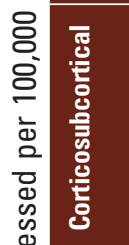

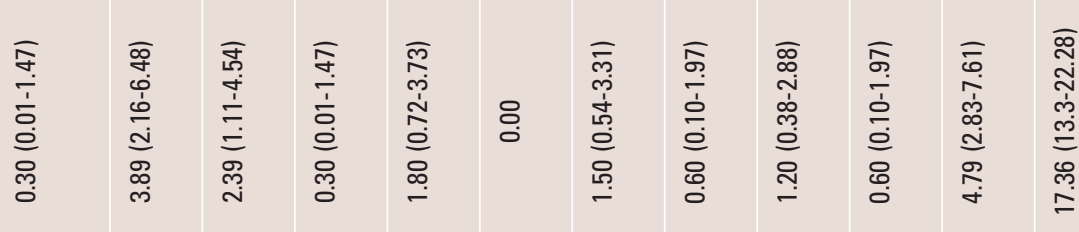

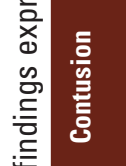

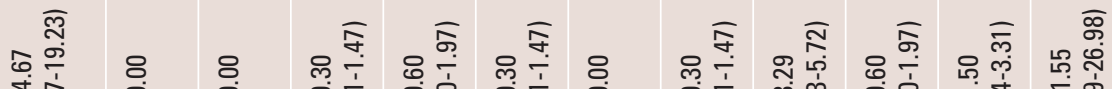

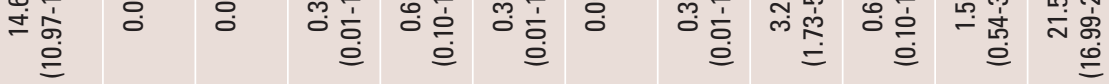

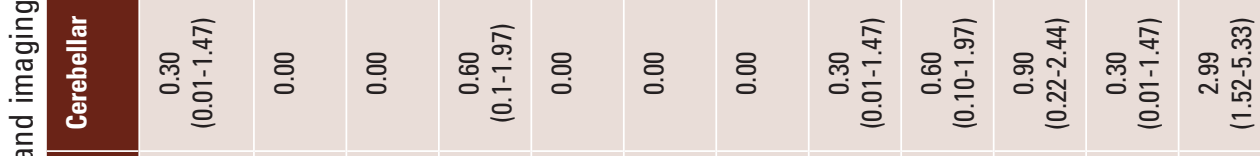

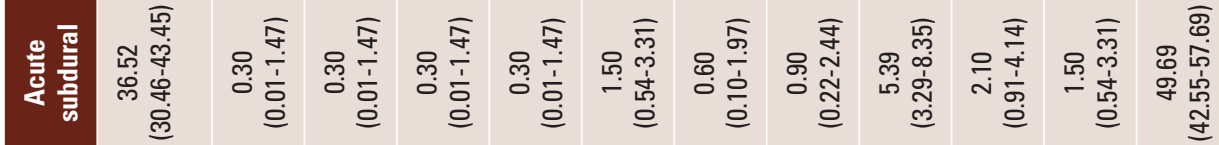

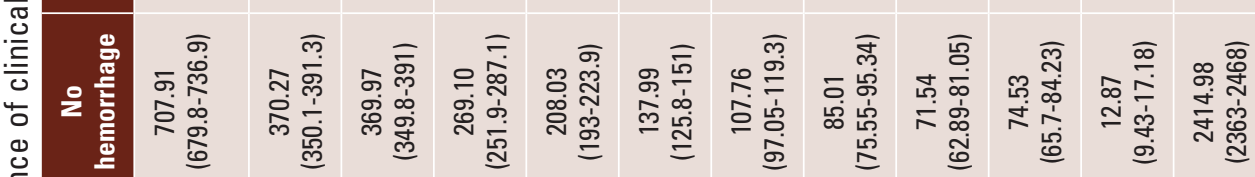

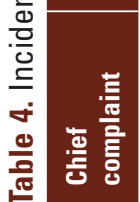

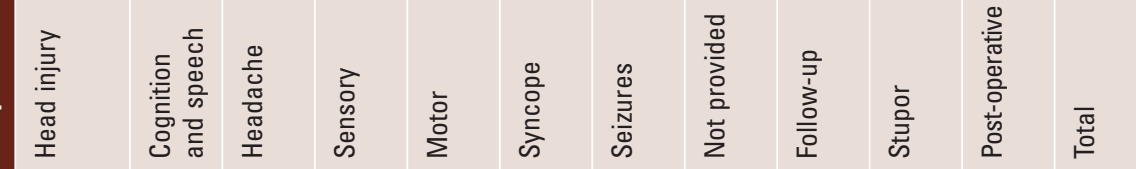


Table 5. Age and gender variations according to clinical context and type of hemorrhage

\begin{tabular}{|l|c|c|c|c|c|c|c|c|c|}
\hline Scenario & $\begin{array}{c}\text { Total } \\
\text { patients }\end{array}$ & Males & Females & M/F ratio & $\begin{array}{c}\text { Mean } \\
\text { age (yy) }\end{array}$ & Median & Min. & Max. & SD \\
\hline Global & 8516 & 3855 & 4661 & 0.83 & 63.31 & 67.72 & 0.15 & 102.30 & 20.24 \\
\hline Head injury & 2564 & 1207 & 1357 & 0.89 & 63.72 & 70.25 & 0.15 & 102.30 & 22.46 \\
\hline Hemorrhage & 448 & 244 & 204 & 1.20 & 66.88 & 71.74 & 0.52 & 97.79 & 19.22 \\
\hline Head injury with hemorrhage & 199 & 122 & 77 & 1.58 & 65.87 & 72.92 & 0.52 & 97.79 & 22.22 \\
\hline Basal ganglia & 61 & 39 & 22 & 1.77 & 73.31 & 74.54 & 40.61 & 91.77 & 11.33 \\
\hline Corticosubcortical spontaneous & 58 & 26 & 32 & 0.81 & 65.97 & 69.62 & 7.62 & 95.50 & 18.35 \\
\hline Chronic subdural & 30 & 15 & 15 & 1.00 & 76.81 & 78.36 & 37.39 & 91.70 & 11.80 \\
\hline Spontaneous subarachnoid & 18 & 4 & 14 & 0.29 & 61.62 & 60.90 & 25.08 & 88.31 & 15.01 \\
\hline
\end{tabular}

and Mediterranean diet, although sedentarism and obesity issues regarded as a growing epidemic; absence of documented peaks of vascular hereditary hemorrhagic pathologies; controlled crime situation and unpermissive use of guns by citizens; mandatory use of helmet by motorcyclists; restrictive speed limit, although concerns regarding its adequate supervision are common; reasonable road quality; and reasonable implementation of measures to prevent work accidents. This should be taken into account in the contextualization of the salient figures of this study that include an incidence rate of intracranial hemorrhage of $134.10 / 100,000 /$ year; a global incidence rate of head injury of $767.48 / 100,000 /$ year; incidence rates of hemorrhagic patterns more likely to be associated with a traumatic origin include acute subdural (49.69), contusion (21.55), and epidural (5.09), adding up to a global incidence rate of $76.33 / 100,000 /$ year; and incidence rates of hemorrhagic patterns more likely to be associated with a spontaneous origin include basal ganglia (18.26), cerebral corticosubcortical spontaneous (17.36), spontaneous subarachnoid (5.39), cerebellar (2.99), and brainstem (1.20), adding up to a global incidence rate of $45.2 / 100,000 /$ year, inferior to the one of trauma. When viewing the difference between these two figures, it is acknowledged that the categorization between traumatic and spontaneous origins may not be straightforward in selected situations. Head injury is the most frequent complaint motivating brain $\mathrm{CT}$ scan $(30.11 \%)$, and in this context, hemorrhage is present in up to $7.76 \%$. The presence of hemorrhage in $44.87 \%$ of post-operative CT scans does not imply a large volume; it includes operated hemorrhages and elective cases and is not synonym with post-operative hematoma requiring surgical evacuation. The "follow-up" category is an unspecific clinical jargon that may harbor diverse situations; given that, this analysis employed the first CT scan of the sequence that patients performed, this category probably includes patients that suffered the original hemorrhagic event before the study period and that may justify the finding of $16.43 \%$ of hemorrhage; the number may also represent those patients that were diagnosed in private settings and then transferred to the public facility during the study period. Hemorrhage is present in $11.07 \%$ of cases of stupor, and this attests the severe clinical condition that hemorrhage may cause. Acute subdural, contusion, and epidural, classically of traumatic origin, add up to $56.91 \%$ of the patterns of hemorrhage found. Although more females undergo brain $\mathrm{CT}$ scan (M/F ratio 0.83), and even so in the context of head injury ( $M / F$ ratio 0.89 ), hemorrhage, in general, is more frequently encountered in males $(M / F$ ratio 1.20 ), including the context of head injury ( $M / F$ ratio 1.58), but excluding spontaneous subarachnoid hemorrhage (M/F ratio 0.29) $(p<0.05$ Fisher's exact with mid-P method). It can be hypothesized that males engage in more accident-prone behavior and adhere less to the control of neurovascular risk factors. Basal ganglia hemorrhage and chronic subdural hemorrhage seem to affect older people (mean age superior to 70$)(p<0.05$ t-test). In the context of head injury and traumatic brain injury, focused published reviews emphasize the considerable variability that exists on the reported incidence rates due to very different inclusion criteria and effective regional variations, ranging from 7.3 to $811 / 100,000 /$ year ${ }^{2}$, with a mean of 262 in Europe $^{3}$. Male predominance and mean age of occurrence ranging from 27 to 59.67 years have been reported as well ${ }^{2}$. The concept of traumatic brain injury as "an alteration in brain function 
or other evidence of brain pathology caused by an external force" ${ }^{\text {"4 }}$ might encompass the cases here reported as head injury with intracranial hemorrhage (76.33/100,000/year obtained by summing acute subdurals, contusions, and epidurals); on the other hand, the complaint head injury alone would measure a much larger phenomenon that includes the very frequent minor trauma with no consequence (reported in the present study as $767.48 / 100,000 /$ year). The population of the present study would rank low in the former situation (major trauma) and high in the latter (minor trauma). For intracerebral hemorrhage reported incidence rates per 100,000 person-years ranged from 19.6 to 51.85 , and the population of the present study would rank high (39.81/100,000/year obtained by summing basal ganglia, cerebral corticosubcortical spontaneous, cerebellar, and brainstem). Spontaneous subarachnoid hemorrhage ranges from 4.2 to $22.7 / 100,000$ person-years ${ }^{6}$; the population of the present study would rank low $(5.39 / 100,000$ person-years). Screening of vascular lesions with modern non-invasive imaging methods in selected high-risk groups is well established ${ }^{7}$, and if feasible, treatment before rupture is advocated in this setting, thereby minimizing the risk of hemorrhage. To what extent should these programs be implemented in settings of high incidence of intracranial hemorrhage could deserve further cost-effect analysis. Surveillance of intracranial hemorrhage incidence in large sampling geographical areas, such as performed in the present study, may disclose potential areas of intervention for the improvement of these rates and of the health status of the community.

\section{Conclusion}

In the population and in the period in study, traumatic patterns of hemorrhage seem to be slightly more frequent than those of spontaneous nature and head injury the most frequent indication for brain CT scan study. Although within the ranges reported in literature, the incidence rates of hemorrhage that were found rank low for trauma and spontaneous subarachnoid and high for intracerebral. Reinforcement of measures aimed at the prevention of head trauma, control of neurovascular risk factors, and screening for vascular pathology may be in order. This indicator serves to characterize the health status of the community.

\section{Acknowledgments}

None.

\section{Conflicts of interest}

None.

\section{Financing}

None.

\section{References}

1. Instituto Nacional de Estatistica, Censos; 2011. Available from: http:// censos.ine.pt/xportal/xmain?xpid=CENSOS\&xpgid=censos_quadros. [Last accessed on 2017 Jul 09].

2. Li M, Zhao Z, Yu G, Zhang J. Epidemiology of traumatic brain injury over the world: a systematic review. Austin Neurol Neurosci. 2016;1:1007.

3. Peeters W, van den Brande R, Polinder S, Brazinova A, Steyerberg EW, Lingsma HF, et al. Epidemiology of traumatic brain injury in Europe. Acta Neurochir (Wien). 2015;157:1683-96.

4. Menon DK, Schwab K, Wright DW, Maas Al, Demographics and Clinical Assessment Working Group of the International and Interagency Initiative toward Common Data Elements for Research on Traumatic Brain Injury and Psychological Health. Position statement: definition of traumatic brain injury. Arch Phys Med Rehabil. 2010;91:1637-40.

5. van Asch CJ, Luitse MJ, Rinkel GJ, van der Tweel I, Algra A, Klijn CJ, et al. Incidence, case fatality, and functional outcome of intracerebral haemorrhage over time, according to age, sex, and ethnic origin: a systematic review and meta-analysis. Lancet Neurol. 2010;9:167-76.

6. de Rooij NK, Linn FH, van der Plas JA, Algra A, Rinkel GJ. Incidence of subarachnoid haemorrhage: a systematic review with emphasis on region, age, gender and time trends. J Neurol Neurosurg Psychiatry. 2007; 78:1365-72.

7. Brown RD Jr., Huston J, Hornung R, Foroud T, Kallmes DF, Kleindorfer D, et al. Screening for brain aneurysm in the familial intracranial aneurysm study: frequency and predictors of lesion detection. J Neurosurg. 2008;108:1132-8. 